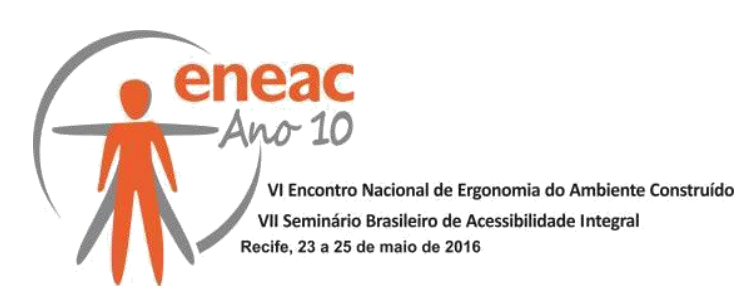

\title{
AVALIAÇÃO DA QUALIDADE ESPACIAL NO ENTORNO DE UM EDIFÍCIO RELIGIOSO
}

\author{
GEBARA, Tatiana R. Jacon (1); \\ MAIA, Marina Lisboa (2); \\ FARIA, Obede Borges (3); \\ FONTES, Maria Solange Gurgel de Castro (4); \\ MAGAGNIN, Renata Cardoso (5)
}

(1) Universidade Estadual Paulista "Julio de Mesquita Filho" - UNESP. Mestranda em Arquitetura e Urbanismo.

e-mail: tatiana gebara@terra.com.br

(2) Universidade Estadual Paulista "Julio de Mesquita Filho" - UNESP. Mestranda em Arquitetura e Urbanismo.

e-mail: mlisboamaia@gmail.com

(3) Universidade Estadual Paulista “Julio de Mesquita Filho" - UNESP; Doutor.

e-mail: obede.faria@gmail.com

(4) Universidade Estadual Paulista "Julio de Mesquita Filho" - UNESP; Doutora.

e-mail:_sgfontes@faac.unesp.br

(5) Universidade Estadual Paulista “Julio de Mesquita Filho" - UNESP; Doutora.

e-mail: magagnin@faac.unesp.br

\begin{abstract}
RESUMO
De uma maneira geral, locais com relevância histórica não foram projetados para atender pessoas com mobilidade reduzida, pois no período de sua construção não existiam normas técnicas para essa finalidade. Nesse contexto, este artigo tem como objetivo analisar a qualidade espacial no espaço contíguo a uma instituição religiosa, tombada pelo patrimônio histórico, localizada na cidade de Bauru (SP), e assim identificar quais são os elementos que podem contribuir para aumentar a qualidade espacial através da acessibilidade. A metodologia utilizada foi vistoria técnica e aplicação de questionários a uma amostra de usuários. Os resultados contribuíram para: evidenciar diversas barreiras arquitetônicas; aplicar uma metodologia de avaliação em ambientes de valor histórico e repensar a utilização dos espaços de uso público para uma faixa etária em ascensão no país.
\end{abstract}

Palavras chave: Espaço Público, Qualidade Espacial, Acessibilidade.

\section{ABSTRACT}

In general, places with historical significance are not designed to serve persons with reduced mobility, for the period of its construction there were no technical standards for this purpose. In this context, this paper aims to analyze the spatial quality in the area next to a religious institution, protect by the 


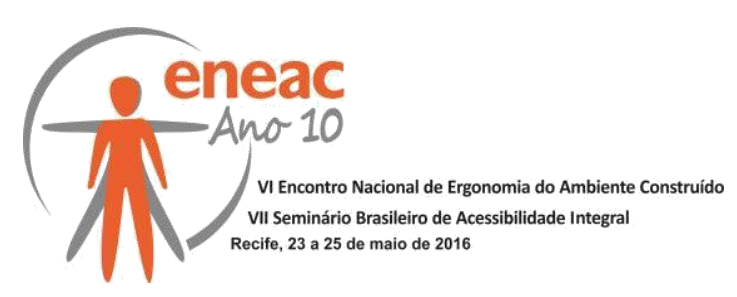

historical heritage, located in the city of Bauru (SP), and so identify what are the elements that can contribute to increase the spatial quality through accessibility. The methodology used was technical inspection and questionnaires to a sample of users. The results contributed to: show the architectural barriers; apply an evaluation methodology in historical value environments and rethink the use of public spaces for an age group ascending in the country.

Keywords: Public Space, Space Quality, Accessibility.

\section{INTRODUÇÃO}

Segundo dados da Organização das Nações Unidas - ONU, atualmente o mundo está passando por um processo de transição demográfica decorrente do processo de envelhecimento da população e da diminuição da taxa de fertilidade. Dados do Instituto Brasileiro de Geografia e Estatística (IBGE) mostram que nos últimos 10 anos (período entre 2000 a 2010) a população brasileira acima de 60 anos cresceu 1,5\%. Os idosos são 20,5 milhões de pessoas, ou seja, aproximadamente $10 \%$ da população total do País. Estima-se que em 20 anos, a população idosa do Brasil poderá ultrapassar os 30 milhões de pessoas e deverá representar quase $13 \%$ da população ao final deste período (IBGE, 2015).

Esses dados mostram que há um aumento na expectativa de vida e, consequentemente, um aumento no número de pessoas com mobilidade reduzida. Assim, é indispensável que as cidades adequem os espaços de uso público a essa faixa etária. Os espaços públicos são afetados por uma complexidade de problemas.

Atualmente, na maioria das cidades brasileiras de médio porte, há um esvaziamento do espaço público no sentido mais amplo da palavra, principalmente nas áreas centrais. Este esvaziamento pode ser atribuído a falta de políticas públicas e programas urbanos, que possam revitalizar esses locais (MAGAGNIN, 1999).

A praça tem uma importância enquanto elemento morfológico da estrutura urbana, pois representa um espaço intersticial entre a rua e a edificação, entre o espaço público e o privado; e sofre influência e interferência dos elementos construídos e não construídos (MAGAGNIN, 1999). Na maioria dos casos, sua função sempre esteve associada em possibilitar e facilitar o acesso dos membros da comunidade à igreja; além de ser o local para a saída e o retorno das procissões; podendo, em outros casos, também servir de recreio e lazer (MARX, 1980).

Em função de seu traçado e por pertencer muitas vezes a uma estrutura urbana consolidada, nem sempre a praça pode ser considerada um ambiente seguro e acessível a todos os usuários. Dentre os elementos que podem contribuir para a segurança dos usuários destacam-se: os percursos internos, a inclinação do piso, as condições de manutenção do piso, a retidão da rota, o esforço despendido, e qualquer outro fator que facilite a caminhada (AGUIAR, 2003; NEIVA E RODRIGUES, 2010).

No entanto, muitos destes locais não estão aptos para receberam pessoas com restrições de mobilidade, pois na época de sua construção não existiam normas e leis que assegurassem esse direito a todos. Atualmente, em função das leis de preservação há certa dificuldade em adaptar estes espaços tornando-os acessíveis (GERENTE, 2005). Para Andrade e Bins Ely (2010) a identidade de uma sociedade precisa ser preservada, garantindo a memória, mas a adequação desses espaços se torna imprescindível.

Segundo Dischinger; Bins Ely; Piardi (2009) o espaço acessível deve permitir que o usuário possa se deslocar com segurança, conforto e autonomia para realizar todas as atividades, independentemente de sua condição ou habilidade física.

Neste contexto, este artigo tem por objetivo analisar a qualidade espacial de um espaço contíguo a uma instituição religiosa, tombada pelo Patrimônio Histórico do município de 


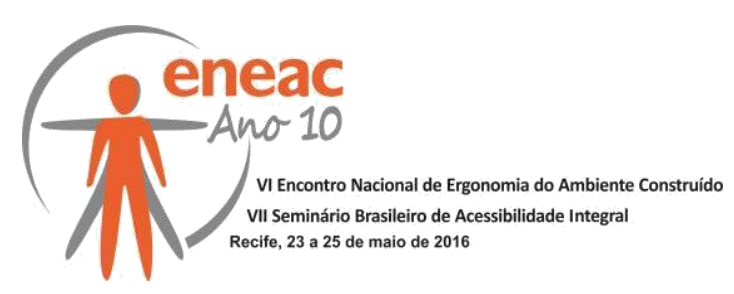

Bauru (SP), para identificar quais elementos podem contribuir para o aumento da qualidade espacial através da acessibilidade.

\section{OBJETO DE ESTUDO}

Para analisar a qualidade espacial no entorno de uma instituição religiosa foi utilizado como objeto de estudo à área do entorno da Igreja Santa Terezinha, situada na área central da cidade de Bauru, localizada na região centro oeste do Estado de São Paulo, ver Figura 1.

Figura 1 - Localização do município no Estado de São Paulo e localização do objeto de estudo na quadra de intervenção

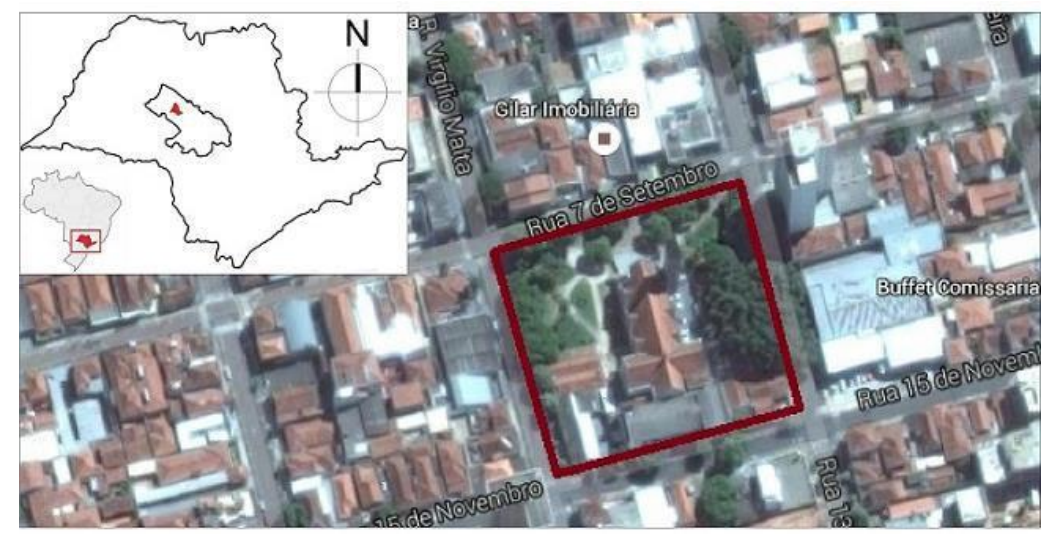

Fonte: Adaptado do Google Maps, 2015.

A Igreja Santa Teresinha do Menino Jesus, inaugurada em 1934, foi tombado pelo Conselho de Defesa do Patrimônio Cultural de Bauru (CODEPAC), em 2002. Na parte frontal à Igreja há uma praça denominada, Praça Rodrigues de Abreu $\left(7.744 \mathrm{~m}^{2}\right)$, e funciona como um espaço de passagem para o acesso à Igreja. O público local mais frenquente é composto por idosos, que de acordo com o IBGE (2010), constitui a faixa etária que mais cresceu nessa década.

\section{MATERIAIS E MÉTODOS}

Para cumprir os objetivos da pesquisa foram realizados: consulta à legislação e as normas técnicas sobre o assunto estudado; levantamentos fotográfico e métrico; aplicação de vistoria técnica e aplicação de questionários.

A primeira etapa da pesquisa consistiu do desenvolvimento de um protocolo (checklist) para avaliação da qualidade espacial no entorno da Igreja, com base na planilha de avaliação de acessibilidade desenvolvida por Dischinger; Bins Ely; Piardi (2012) e na norma técnica de acessibilidade, NBR 9050/2004 (vigente no período da pesquisa). O checklist permitiu avaliar os passeios e os acessos da praça até a entrada do edificio através dos seguintes elementos: largura livre efetiva, tipo de piso, manutenção do piso, nivelamento do piso, desníveis e inclinações. Os indicadores foram avaliados através de dois parâmetros: ambiente acessível (atende 100\% das recomendações da NBR 9050) e ambiente não acessível (não atende as diretrizes da norma técnica de acessibilidade). 


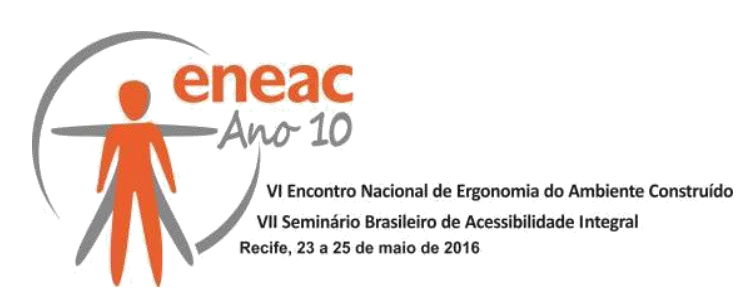

Na sequência foi realizada a aplicação da vistoria técnica e o levantamento fotográfico que permitiram identificar os principais problemas associados a qualidade espacial deste local. Para a aplicação da vistoria técnica, foi necessário definir as principais rotas de acesso à igreja (Figura 2). As rotas representam um percurso livre de qualquer obstáculo de um ponto a outro, levando em consideração medidas de acessibilidade (GUIMARÃES, 2000).

\section{Figura 2 - Definição das rotas para análise da qualidade espacial}

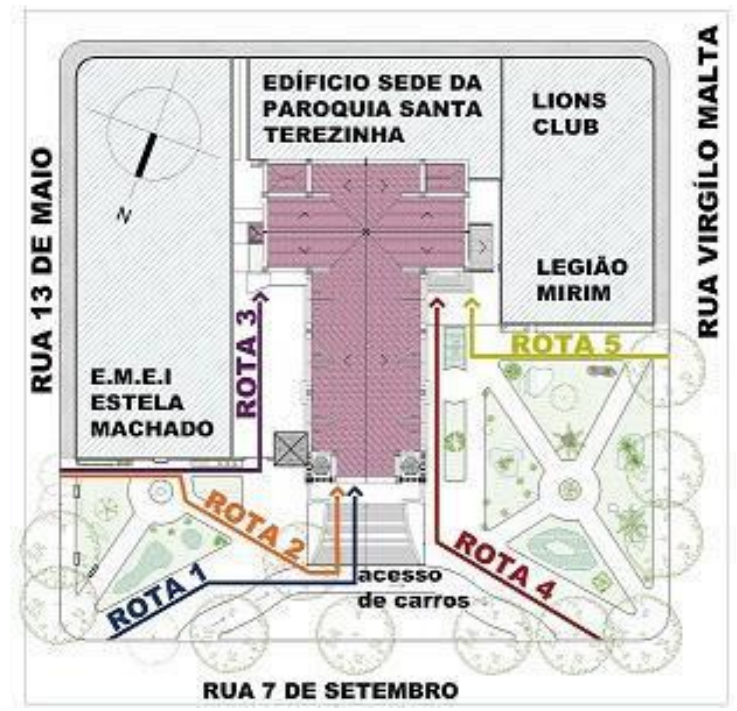

Fonte: Elaborado pelas autoras, 2015.

A Rota 1 refere-se ao trajeto compreendido pela lateral esquerda até a escadaria da igreja. A Rota 2 também permite o acesso pela lateral esquesrda da Igreja, no entanto, o percurso tem início na Rua 13 de Maio, passa em frente da entrada de uma escola de ensino infantil até acessar a escadaria frontal da Igreja.

A Rota 03 tem origem junto a Rota 2, no entanto, os usuários que utilizam este trajeto acessam a igreja pala entrada lateral esquerda. A Rota 4 tem início na lateral direita da quadra da igreja até a entrada lateral direita. Observou-se que esta é a rota mais utilizada pelos usuários. A última rota (Rota 5) é compreendida pelo percurso que tem início na lateral direita da igreja até a porta lateral; esta rota é a de menor fluxo de pessoas.

$\mathrm{Na}$ segunda etapa foram aplicados questionários, que permitiram avaliar alguns problemas relacionados a acessibilidade espacial enfrentados pelos usuários da igreja. As questões eram compostas por perguntas fechadas, de múltipla escolha. Para a definição do universo de análise utilizou-se como referência os estudos realizados por Ornstein e Romero (2003). Foi adotada uma margem de erro de $10 \%$ e um nível de confiança de $95,5 \%$, o que resultou numa amostra mínima final de 42 entrevistas. Os entrevistados foram classificados três grupos sendo, o primeiro grupo composto por usuários com mais de 60 anos (19 questionários), o segundo grupo, com usuários até 60 anos (10 questionários) e o terceiro grupo que abrangeu os usuários que não responderam sua faixa etária (13 questionários). A aplicação dos questionários foi realizada entre os meses de julho e agosto de 2015. Os elementos avaliados foram: tipo de piso, função da praça, número de vagas de estacionamento, e o acesso à igreja. 


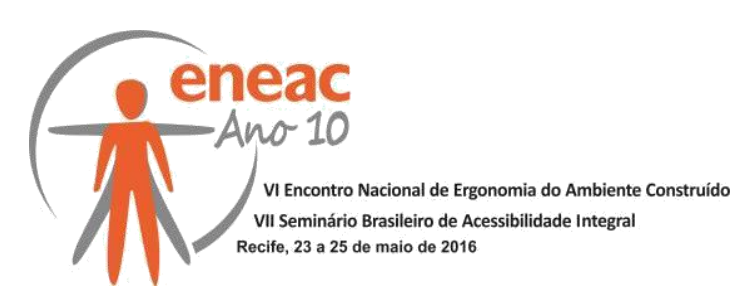

\section{ANÁLISE DOS RESULTADOS}

Os resultados obtidos são apresentados na seguinte ordem: análise da qualidade espacial através da técnica de vistoria e análise da acessibilidade sob o ponto de vista do usuário.

\subsection{Análise da qualidade espacial através de Vistoria Técnica}

Para avaliar a qualidade espacial no entorno do edifício da Igreja Santa Teresinha do Menino Jesus os diferentes percursos foram analisados através da definição das principais rotas realizadas pelos usuários da Igreja, conforme mostrou a Figura 02. A Tabela 1 apresenta um resumo da avaliação das Rotas 1 a 5.

Tabela 1 - Análise da acessibilidade das Rotas

\begin{tabular}{|c|c|c|c|}
\hline \multirow{2}{*}{ ROTA } & \multirow{2}{*}{ Indicador } & \multicolumn{2}{|c|}{ Acessibilidade } \\
\hline & & Sim & Não \\
\hline \multirow[t]{7}{*}{ ROTA 1} & Largura efetiva (mínimo 1,20m) & $\sqrt{ }$ & \\
\hline & Tipo de Piso (antiderrapante e regular) & & $\sqrt{ }$ \\
\hline & Manutenção do Piso & & $\sqrt{ }$ \\
\hline & Nivelamento do Piso & & $\sqrt{ }$ \\
\hline & Desnível (inferior a 15mm) & & $\sqrt{ }$ \\
\hline & Inclinação & $\sqrt{ }$ & \\
\hline & & & essibilidade \\
\hline \multirow[t]{7}{*}{ ROTA 2} & Largura efetiva (mínimo 1,20m) & & $\sqrt{ }$ \\
\hline & Tipo de Piso (antiderrapante e regular) & & $\sqrt{ }$ \\
\hline & Manutenção do Piso & & $\sqrt{ }$ \\
\hline & Nivelamento do Piso & & $\sqrt{ }$ \\
\hline & Desnível (inferior a 15mm) & & $\sqrt{ }$ \\
\hline & Inclinação & $\sqrt{ }$ & \\
\hline & & & essibilidade \\
\hline \multirow[t]{7}{*}{ ROTA 3} & Largura efetiva (mínimo 1,20m) & $\sqrt{ }$ & \\
\hline & Tipo de Piso (antiderrapante e regular) & $\sqrt{ }$ & \\
\hline & Manutenção do Piso & & $\sqrt{ }$ \\
\hline & Nivelamento do Piso & & $\sqrt{ }$ \\
\hline & Desnível (inferior a 15mm) & & $\sqrt{ }$ \\
\hline & Inclinação & & $\sqrt{ }$ \\
\hline & & & essibilidade \\
\hline \multirow[t]{2}{*}{ ROTA 4} & Largura efetiva (mínimo 1,20m) & $\sqrt{ }$ & \\
\hline & Tipo de Piso (antiderrapante e regular) & $\sqrt{ }$ & \\
\hline
\end{tabular}




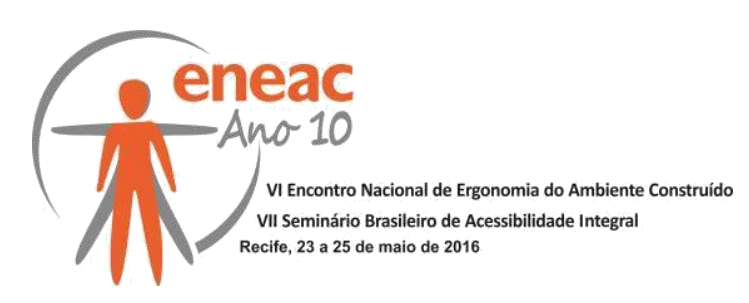

\begin{tabular}{|c|c|c|c|}
\hline \multirow{7}{*}{ ROTA } & \multirow{2}{*}{ Indicador } & \multicolumn{2}{|c|}{ Acessibilidade } \\
\hline & & Sim & Não \\
\hline & Manutenção do Piso & & $\sqrt{ }$ \\
\hline & Nivelamento do Piso & & $\sqrt{ }$ \\
\hline & Desnível (inferior a 15mm) & $\sqrt{ }$ & \\
\hline & Inclinação & $\sqrt{ }$ & \\
\hline & \multicolumn{3}{|c|}{$67 \%$ de acessibilidade } \\
\hline \multirow[t]{7}{*}{ ROTA 5} & Largura efetiva (mínimo 1,20m) & $\sqrt{ }$ & \\
\hline & Tipo de Piso (antiderrapante e regular) & $\sqrt{ }$ & \\
\hline & Manutenção do Piso & & $\sqrt{ }$ \\
\hline & Nivelamento do Piso & & $\sqrt{ }$ \\
\hline & Desnível (inferior a 15mm) & $\sqrt{ }$ & \\
\hline & Inclinação & $\sqrt{ }$ & \\
\hline & & & essibilidade \\
\hline
\end{tabular}

Os dados apresentados na Tabela 1 mostram que os principais problemas referem-se à manutenção e nivelamento do piso - identificado em todas as rotas analisadas. Em função de parte do piso da Praça Rodrigues de Abreu ser composto por pedra portuguesa (piso original de sua implantação), a falta de manutenção e a falta de mão de obra especializada para realizar os reparos necessários nestes caminhos contribuem para uma avaliação negativa em relação à acessibilidade espacial.

Problemas relacionados a presença de desnível do piso, acima do recomendado pela NBR 9050 , foram encontrados em $60 \%$ das rotas analisadas. Os demais problemas obtiveram uma pontuação inferior a $40 \%$.

Analisando cada rota individualmente, pode-se observar que na Rota 1 os principais problemas foram: a falta de um caminho para o pedestre acessar o trajeto compreendido entre a calçada e a escada principal da Igreja; tipo de piso implantado no local: pedra portuguesa. Parte do trajeto analisado está com assentamento do piso irregular, em algumas áreas as pedras estão soltas, Há também falta de manutenção do piso (ver Figura $3 \mathrm{k}$ e 3I). Neste percurso o usuário necessariamente precisa atravessar a via de desembarque de passageiros localizada na frente da Igreja (ver Figura 3k). O índice de acessibilidade calculado para esta rota foi de $33 \%$.

Os problemas de acessibilidade espacial encontrados na Rota 2 foram: trajetos muito estreitos, o que pode comprometer a passagem de um idoso junto com um acompanhante; presença de desníveis no piso causado pela falta de manutenção ou a falta de mão de obra especializada no assentamento das pedras portuguesas, o que pode dificultar o acesso de pessoas com mobilidade reduzida (ver Figuras $3 \mathrm{a}, 3 \mathrm{~b}$ e $3 \mathrm{c}$ ). Diante dos problemas encontrados o índice de acessibilidade encontrado foi de 17\%.

Uma parte do trajeto da Rota 3 sobrepõe-se a Rota 2. Na análise deste percurso mostrou que $33 \%$ dos elementos analisados contribuem para a acessibilidade do local. Dentre os problemas destacam-se: a falta de manutenção do piso (ver Figura 3j); a presença de desnível e inclinação, este último deve-se a presença de uma rampa para acesso ao interior da Igreja cuja inclinação está muito acima da recomendação da NBR 9050 (ver Figura 3d). 


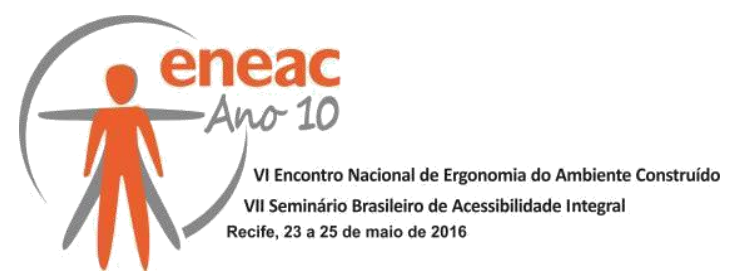

A Rota 4 é o percurso mais acessado pelos usuários da lgreja Santa Terezinha. Seus caminhos são mais acessíveis se comparado as demais rotas, pois este espaço foi reformado; seu piso é de concreto, a largura do passeio é maior, a inclinação é suave e não possui desníveis em toda a sua extensão, o que resultou em um índice de acessibilidade de $67 \%$. Os únicos problemas encontrados referiram-se a falta de manutenção e nivelamento do piso (ver Figura 3g).

Assim como a Rota anterior, a Rota 5 também oferece um dos melhores índices de acessibilidade, $67 \%$. A largura do passeio atende a NBR 9050, possui desnível e inclinação do piso suave $O$ piso é de concreto rústico, o que o torna antiderrapante; ele encontra-se regular, precisando somente de poucas manutenções (ver Figura 3i).

Com relação a presença de mobiliário urbano, bancos e lixeiras, estes não foram encontrados no local. A iluminação noturna é ruim, o que torna o espaço pouco seguro para a comunidade à noite.

Figura 3 - Mapa com diagnóstico das rotas analisadas
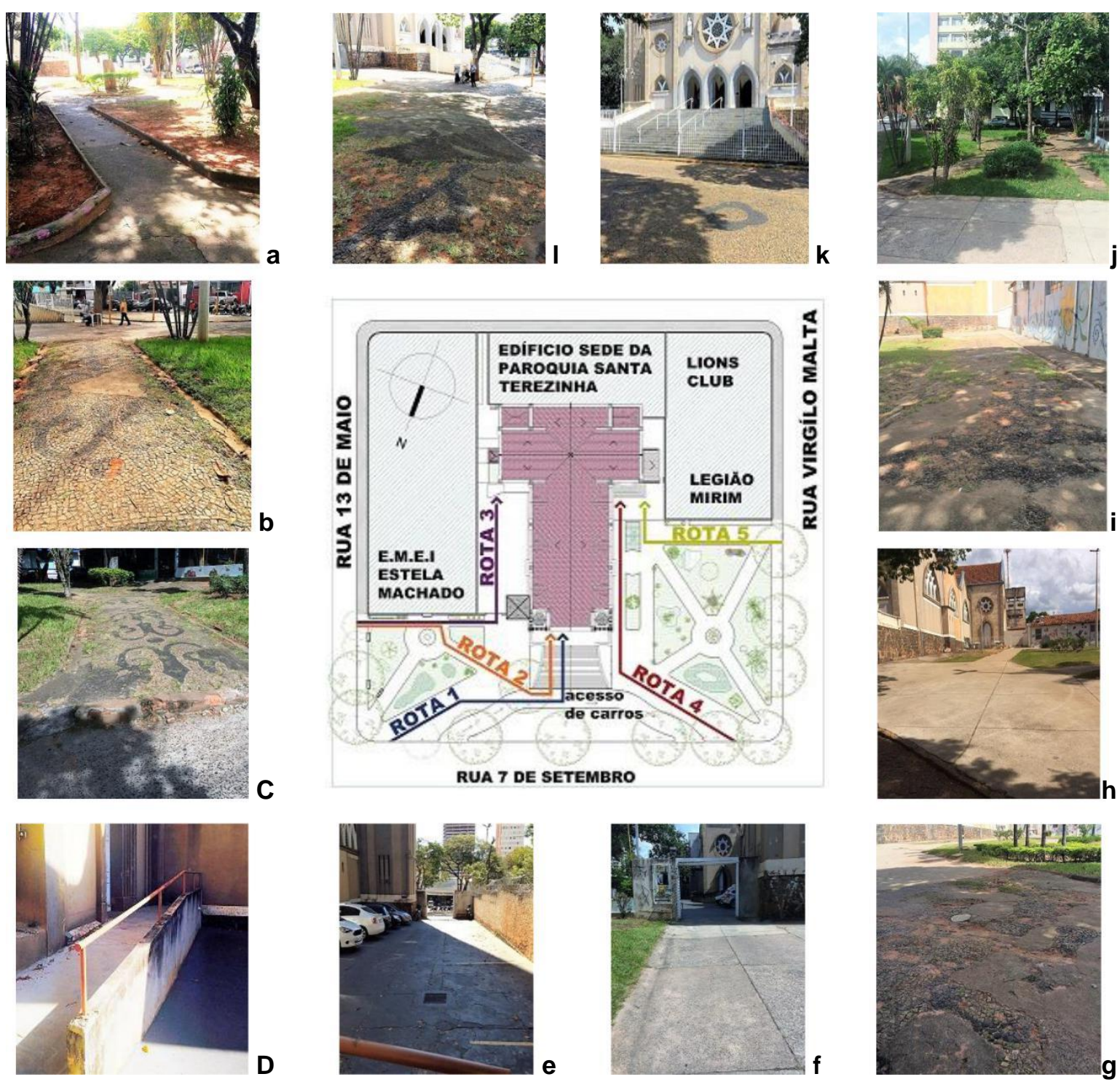

Fonte: Elaborado pelas autoras, 2015. 


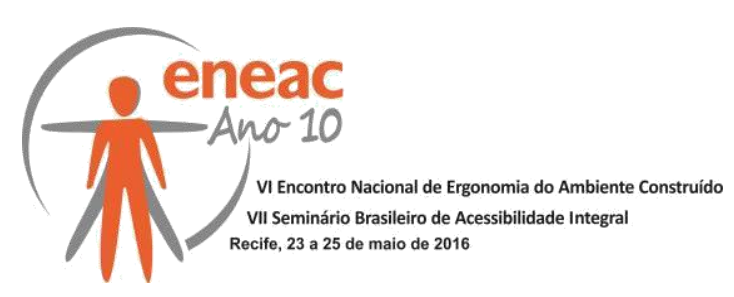

\subsection{Questionário}

Para avaliar se os usuários da Igreja Santa Terezinha enfrentam alguns problemas relacionados a acessibilidade espacial foram aplicados questionários. Para isso, o modelo de questionário foi dividido em duas etapas: a primeira para identificar o espaço da praça Rodrigues de Abreu e o segundo com informações do espaço adjacente a igreja. As perguntas referiram-se a condição dos passeios, a utilização da praça, do estacionamento e dos acessos à Igreja e os resultados são apresentados nas Figuras 04 a 09.

Figura 4 - Tipo de Piso

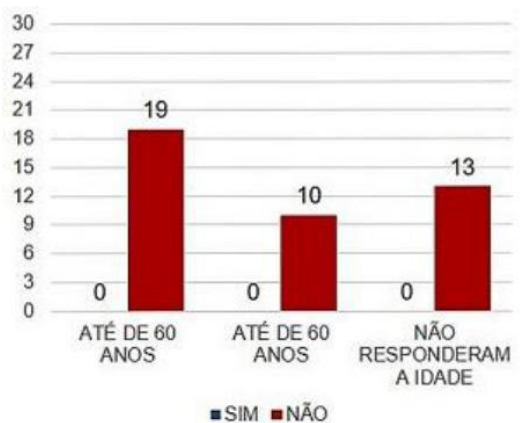

Figura 5 - Função da Praça

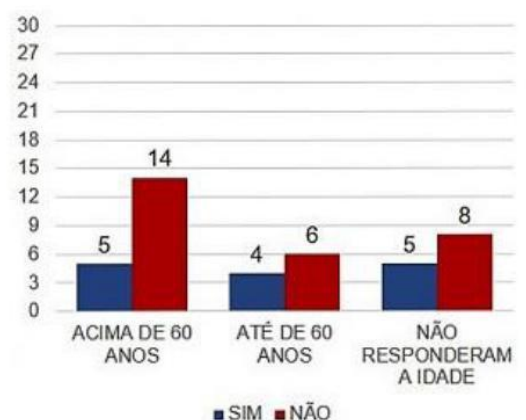

Figura 6 - Vagas de estacionamento

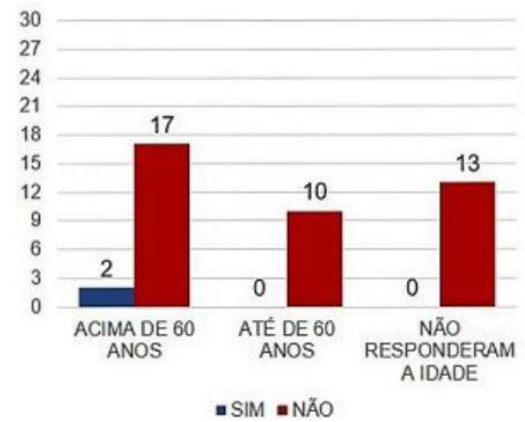

Em relação aos espaços da praça a primeira pergunta referiu-se as condiçõe do calçamento dos passeios, neste item todos os usuários (100\% das respostas) informaram que embora 0 piso fosse de pedra portuguesa com assentamento nem sempre regular, nunca tiveram qualquer problema de mobilidade. Em relação a função da praça 66,66\% das respostas informaram que ela é apenas um local de passagem; a falta de segurança (policiamento) pode ser um fator que contribui para estas respostas. Em relação a quantidade de vagas de estacionamento, mais de $95 \%$ dos usuários acham que não possui estacionamento suficiente para os carros. Sobre isso, pode-se observar, em visitas ao local, que a maioria dos usuários utilizam o interior da praça como estacionamento para seus veículos.

Figura 7 - Acesso à igreja através de escadas

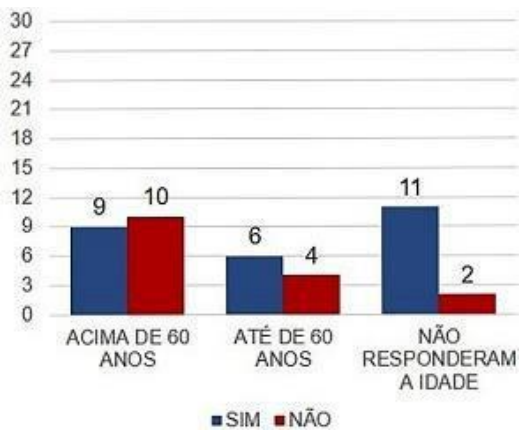

Figura 8 - Acesso à igreja através da rampa lateral

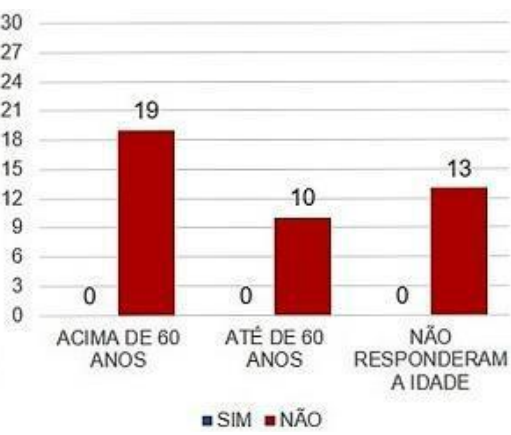

Figura 9 - Acesso à igreja através da escada lateral

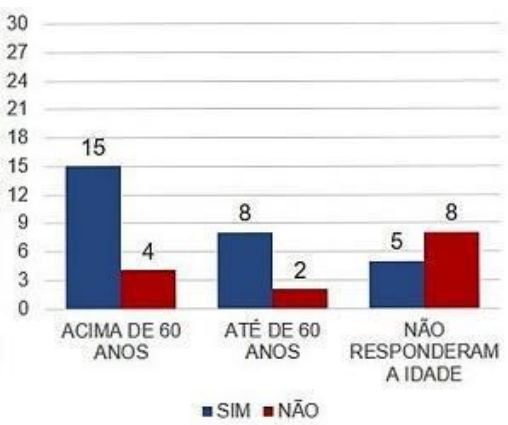




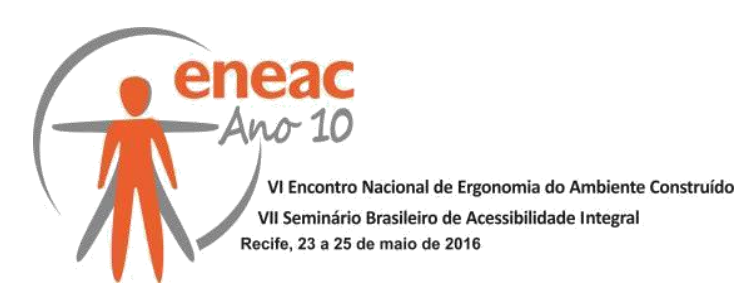

Nas questões referentes ao espaço adjacente à Igreja, $61,90 \%$ dos entrevistados informaram que, em função da idade, tem alguma dificuldade para subir a escada principal. Porém, nenhum usuário informou que já utilizou a rampa lateral para acessar a Igreja, mas apenas a escada lateral. Em relação ao acesso à Igreja pelas outras duas entradas laterais, por rampa e pela escada, os resultados das entrevistas mostraram que nenhum usuário acessa a igreja através da rampa lateral, mesmo este acesso estar localizado próximo ao estacionamento da igreja. Em relação a outra entrada lateral, $66,67 \%$ afirmaram que utilizam esta entrada, é neste lado que se concentra a maior parte dos carros estacionados, sendo a grande maioria no interior da praça.

Esses resultados ressaltam que as principais dificuldades dos usuários estão relacionadas à manutenção e nivelamento do piso, que em grande parte é constituído de pedra portuguesa. Assim, comprova-se que a segurança do usuário não é levada em consideração, pois a maioria dos usuários é idosa e consequentemente, muitos têm mobilidade reduzida.

Apesar das condições arriscadas de espacial no espaço, $100 \%$ dos usuários entrevistados informaram que no entorno da igreja não há problema de acessibilidade espacial. No entanto, a vistoria técnica constatou que o estado de manutenção deste espaço, em termos de acessibilidade é crítico. Supõe-se que em função do apego e da identidade que estes usuários têm com a igreja impossibilita que eles possam enxergar os problemas identificados no local.

\section{CONSIDERAÇÕES FINAIS}

Através das análises pode-se observar que o indivíduo pode estar ativo e integrado ao convívio social, independentemente de terem mobilidade reduzida ou não. Dischinger, Bins Ely, Piardi (2012) entendem que a acessibilidade espacial se refere a integração entre as pessoas com 0 ambiente por todos os usuários independente de suas habilidades ou limitações, existem diversos exemplos de pessoas com deficiência ou mobilidade reduzida e cada pessoa tem um grau de dificuldade, e por ser tão amplo é difícil conseguir fazer com que um ambiente seja totalmente acessível a todos.

Através da aplicação da técnica de vistoria técnica constatou-se que existem muitos problemas em relação ao espaço da Praça Rodrigues de Abreu, que poderiam ser resolvidos facilmente, com a manutenção dos pisos e adequação de mobiliário urbano. Em relação ao espaço contíguo a igreja, os problemas identificados necessitam de estudos adequados ao local sem descaracterizar o objeto arquitetônico. Já os resultados da aplicação dos questionários evidenciam que, apesar das diversas deficiências, o imenso valor histórico e religioso supera as questões relacionadas as barreiras arquitetônicas. Por isso, não deixam de frequentar o local.

Essa pesquisa não visa a solução de todos dos problemas dos usuários, mas buscar compreender os problemas com o fim de minimiza-los; contribuir com uma metodologia de avaliação de ambientes de valor histórico, além de repensar os espaços de uso público para uma faixa etária em ascensão no país.

\section{BIBLIOGRAFIA}

AGUIAR, F. O. Análise de métodos para a avaliação da qualidade de calçadas. Dissertação (Mestrado). Engenharia Urbana. Universidade Federal de São Carlos. 2003. 


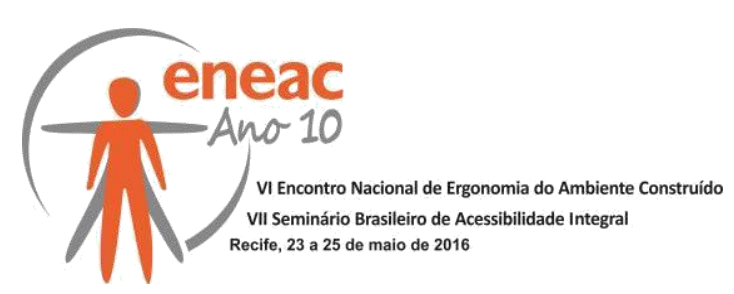

ANDRADE, I. F.; BINS ELY, V. H. M. Acessibilidade em edificações históricas: avaliando o caso de Pelotas. Ação Ergonômica: Revista Brasileira de Ergonomia. V. 5, $\mathrm{n}^{\circ} 2$ 2. 2010. Disponível em: < http://www.abergo.org.br/revista/index.php/ae/article/view/86>. Acesso em: 21/01/2016.

ASSOCIAÇÃO BRASILEIRA DE NORMAS TÉCNICAS. NBR 9050: Acessibilidade de pessoas portadoras de deficiência a edificações, espaço, mobiliário e equipamentos urbanos. Rio de Janeiro. 2004.

AXELSON, P. W; KIRSCHBAUM, J. B; LONGMUIR, P. E; MIRSPAGEL, K. M; STEIN, J.A; YAMADA, D. A. Designing Sidewalks and trails for Access. Part II of II: Best Practice Design Guide. 2001.

BRASIL. Ministério das Cidades. Brasil Acessível. Programa brasileiro de acessibilidade urbana. Cadernos 1, 2, 3, 4, 5 e 6. Secretaria Nacional de Transporte e da Mobilidade Urbana. Brasília, 2007.

DESHAIES, B. Metodologia da investigação em ciências humanas; Lisboa: Instituto Piaget, 1992.

DISCHINGER, M., BINS ELY, V.H.M. e PIARDI, S. M. D. G. Manual de Acessibilidade. Promovendo acessibilidade espacial nos edifícios públicos. Florianópolis, 2012.

DISCHINGER, M; BINS ELY, V. H.; PIARDI, S. M. D. G. Promovendo a acessibilidade nos edifícios públicos: Programa de Acessibilidade às Pessoas com Deficiência ou Mobilidade Reduzida nas Edificações de Uso Público. Florianópolis: Ministério Público de Santa Catarina, 2009.

DUARTE, C. R. S.; COHEN, R. (2006). Proposta de Metodologia de Avaliação da Acessibilidade aos Espaços de Ensino Fundamental. In: Anais NUTAU 2006: Demandas Sociais, Inovações Tecnológicas e a Cidade. SP, USP

FERREIRA, F. M. C.; SOUZA, H. S. Um olhar sobre o patrimônio: levantamento da acessibilidade do conjunto arquitetônico da Basílica do Senhor Bom Jesus de Matosinhos, Congonhas-MG. Ação Ergonômica. Revista Brasileira de Ergonomia, 2012.

GERENTE, M. M. Introduzindo diretrizes de projeto para a acessibilidade em sítios históricos a partir do estudo de São Francisco do Sul. Dissertação (Mestrado). Pós-graduação em Arquitetura e Urbanismo. UFSC. Florianópolis, 2005.

GUIMARÃES, M. P. Acessibilidade: Diretriz para a Inclusão. Revista USP. v. 1, p. 1- 9, 2000.

INSTITUTO BRASILEIRO DE GEOGRAFIA E ESTATÍSTICA. Censo 2010: Pessoas com deficiência $\quad$ - $\quad$ amostra. $2016.20 \mathrm{Disponível}$ <http://cidades.ibge.gov.br/xtras/perfil.php?lang=\&codmun=350600> (Acesso em 18/01/2016).

INSTITUTO NACIONAL DE TECNOLOGIA. Ergonomia para melhorar a qualidade de vida dos idosos. - Disponível em: <https://www.int.gov.br/sala-de-imprensa/noticias/item/6757-ergonomiapode-melhorar-qualidade-de-vida-dos-idosos. Acesso em 27/01/2016.

MAGAGNIN, R. C. Análise de desempenho espacial e perceptiva do espaço público: 0 caso da Avenida São Carlos. Dissertação (Mestrado). Pós-graduação em Engenharia Urbana. UFSCar. São Carlos, 1999.

MAGAGNIN, R. C. Cidades Acessíveis: o planejamento da infraestrutura para a circulação de pedestres. In: Maria Solange G. de Castro Fontes, Norma Regina T. Constantino e Luis Cláudio Bittencourt (Org.). Arquitetura e Urbanismo: novos desafios para o século XXI. Canal 6. Bauru. 2009.

MAGAGNIN, R. C.; VANDERLEI, C. B. Em busca de cidades acessíveis: cálculo do grau de acessibilidade para a infraestrutura destinada aos pedestres na Avenida Duque de Caxias em Bauru (SP). IV Encontro Nacional de Ergonomia do Ambiente Construído e V Seminário Brasileiro de Acessibilidade Integral. Florianópolis/SC 2013. 


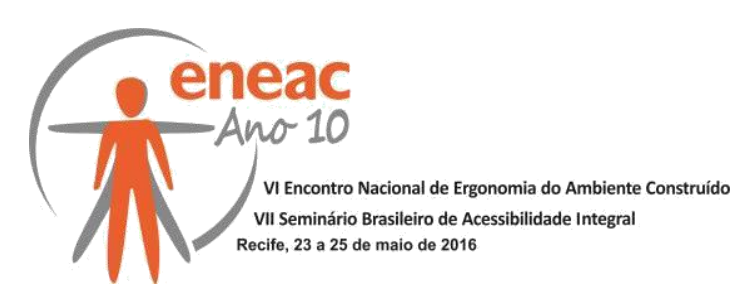

MARX, M. Cidades Brasileiras. São Paulo. EDUSP, 1980.

NEIVA, C. L.; RODRIGUES, D. S. Classificação de redes pedonais para pessoas com mobilidade reduzida. In: 4 Congresso Luso Brasileiro para o Planeamento urbano, Regional, Integrado e Sustentável - PLURIS 201. Anais.... Portugal. Universidade do Algarve. 2010.

PREFEITURA MUNICIPAL DE BAURU. Publicação Diário Oficial de 15/03/2008 - Disponível em: <http://www.bauru.sp.gov.br/juridico/diariooficial.aspx>. Acesso em 25/01/2016).

PREFEITURA MUNICIPAL DE BAURU. Secretaria de Planejamento. 2016. Disponível em: $<$ http://www.bauru.sp.gov.br/seplan/legislacoes.aspx>. Acesso em 18/01/2016.

REIS FILHO, N. G. Contribuição ao estudo da evolução urbana no Brasil (1500/ 1720). São Paulo: EDUSP, 1968. 